\title{
Acoustic emission activity in directly tensile test on marble specimens and its tensile damage constitutive model
}

\author{
Ruifu Yuan ${ }^{1,2} \cdot$ Bowen Shi ${ }^{1}$
}

Received: 29 September 2017/Revised: 16 May 2018/Accepted: 29 August 2018/Published online: 21 September 2018

(C) The Author(s) 2018

\begin{abstract}
For understanding acoustic emission (AE) activity and accumulation of micro-damage inside rock under pure tensile state, the $\mathrm{AE}$ signals has been monitored on the test of directly tension on two kinds of marble specimens. A tensile constitutive model was proposed with the damage factor calculated by AE energy rate. The tensile strength of marble was discrete obviously and was sensitive to the inside microdefects and grain composition. With increasing of loading, the tensile stress-strain curve obviously showed nonlinear with the tensile tangent modulus decreasing. In repeated loading cycle, the tensile elastic modulus was less than that in the previous loading cycle because of the generation of micro damage during the prior loading. It means the linear weakening occurring in the specimens. The AE activity was corresponding with occurrence of nonlinear deformation. In the initial loading stage which only elastic deformation happened on the specimens, there were few AE events occurred; while when the nonlinear deformation happened with increasing of loading, lots of $\mathrm{AE}$ events were generated. The quantity and energy of $\mathrm{AE}$ events were proportionally related to the variation of tensile tangent modulus. The Kaiser effect of AE activity could be clearly observed in tensile cycle loading. Based on the theory of damage mechanics, the damage factor was defined by AE energy rate and the tensile damage constitutive model was proposed which only needed two property constants. The theoretical stress-strain curve was well fitted with the curve plotted with tested datum and the two property constants were easily gotten by the laboratory testing.
\end{abstract}

Keywords Marble specimens - Direct tensile test - Acoustic emission - Tensile tangent modulus - Damage constitutive model

\section{Introduction}

Acoustic emission (AE) or microseismic (MS) technology have become an important mean to study rock failure process and determine stability of rock mass because of its capability in real-time monitoring of signal released by rock in external damage (Liu et al. 2017; Přikryl et al.

Ruifu Yuan

yrf@hpu.edu.cn

1 School of Energy Science and Engineering, Henan Polytechnic University, Jiaozuo 454003, Henan, China

2 Collaborative Innovation Center of Coal Work Safety of Henan Province, Jiaozuo 454003, Henan, China
2003; Xiao et al. 2016; Wang et al. 2017; Cao et al. 2016; Hall et al. 2006; He et al. 2014; Li and Li 2017). After excavation of underground engineering, the free side of rock mass tends to be under tensile state which adversely affects stability of the underground rock engineering. The mechanical responses of rock material under pressure and tensile state are quite different. Therefore, AE signal characteristics and constitutive model of the rock under the tensile state need to be studied exclusively.

The generation and propagation of cracks inside rock under compressive stress are very complex, which contain shear fracture, tensile fracture and also accompanied by sliding friction between the damage surface and particles. All of the generation of fractures, vibration and friction could produce $\mathrm{AE}$ signals, resulting in difficulty in 
identification and in-depth analysis of AE signal (Katsuyama 1996). Brazil split method is preferentially adopted in rock tensile test (ISRM 1978). The inner stress distribution of cylindrical specimen subjected to radial loading is more complicated, and highly concentrated compressive stress is around the vicinity of the loading point, while tensile stress dominates in the vicinity of specimen center, so it is difficult to distinguish the generation mechanism of AE signals in Brazil split tests. The mechanism of rock fracture under directs tensile is simpler; the internal microfracture is caused by tensile stress only. The AE signal also corresponds to tensile fracture. The physical basis is more reasonable to propose tensile constitutive model with $\mathrm{AE}$ signals as the damage factor for rock materials.

Stavrogin et al. (1986) carried out direct tensile, splitting and uniaxial compression $\mathrm{AE}$ tests on sandstone and limestone specimens. The results showed that $\mathrm{AE}$ activities of rock specimens under direct tensile was different from that of splitting and uniaxial compression. There were few $\mathrm{AE}$ events in the whole process, which can only be monitored when rock specimen was nearly destructed. Li et al. (2010) carried out uniaxial compression and direct tensile tests on two typical hard rock and soft rock specimens. The relationship between tensile stress, strain and $\mathrm{AE}$ count rate was obtained. Their results showed that, under tensile stress, there was basically no $\mathrm{AE}$ event during initial loading but sudden increasing of $\mathrm{AE}$ occurs before destruction. Nasseri et al. (2011) conducted fracture toughness measurements in granites and $\mathrm{AE}$ technique was adopted to monitor real-time crack initiation and propagation under tension, the creation of a significant fracture process zone surrounding the propagating main crack was been confirmed. Chen et al. (2012), Li et al. (2013) studied $\mathrm{AE}$ characteristics of Beishan granite under direct tensile, uniaxial compression and triaxial compression, and founded influence of different stress conditions on rock failure and $\mathrm{AE}$ characteristics. It is considered that initiation and expansion of fracture under the condition of tensile stress are the main mechanism to control specimen destruction, which leads to later appearance of $\mathrm{AE}$ signal. AE signal will accumulate rapidly once it occurs, which means macroscopic damage occurrence of specimen. Tham et al. (2005) analyzed direct tensile mechanical properties and AE activity of 2-D rock specimens and associated acoustic emission, regarding that AE activity associated with microfractures.

In the aspect of direct tensile damage model of rock, Jin and Qian (1998) proposed nonlinear elasticity constitutive equation by analyzing increasing law of inelastic deformation under tensile stress. Yu et al. (1998) obtained the relationship between energy consumption in tensile damage and internal damage by direct tensile static, dynamic failure experiments and optical analysis of the failure surface. Based on the micro-cracks propagation criterion and extended rate hypothesis, Jiang et al. (2013) obtained damage change and evolution direction of the rock by using integral principle. The damage constitutive equation of the brittle rock under uniaxial tension was established.

Rock is a natural geological material consisting mineral particles and pore fissures in complex distribution. Due to its strong non-uniform characteristics, it is difficult to determine the variation of micro-damage within the rock. In the above theoretical models, damage variables are mostly guided by single fracture propagation, and then the rock is assumed to agree with statistical distribution law. In fact, generation and propagation of rock damage will release corresponding AE signals. Therefore, there is physical significance in definition of damage factor with $\mathrm{AE}$ signals. In addition, the above direct tensile $\mathrm{AE}$ test results also show that $\mathrm{AE}$ activity under direct tension is significantly different from that under compression. If existence of massive tensile micro-damage can be determined by monitoring $\mathrm{AE}$ signals and tensile damage model, it will be of great help to determine stability of rock engineering. In this paper, direct tensile test was conducted on two kinds of marble with monitoring the AE activity, and tensile damage constitutive model was established based on $\mathrm{AE}$ parameters to explore failure mechanism of direct tensile status on marble.

\section{Experiment method}

A pair of spherical hinge pullers was used to eliminate the unevenness on two ends the specimen, so that tensile stress can be axially centered. Two threaded steel caps were used to connect the specimen and the spherical hinge puller. One end of transmission steel cap adopted threaded connection puller, while the other end was processed into a flat surface and stuck with the specimen. Acrylate adhesive was selected, whose tensile strength was up to $24 \mathrm{MPa}$, which met tensile test requirements of most rock.

The rock specimens were drilled from two kinds of marble base which were pink coarse-grained marble and white fine-grained marble, and were processed into D50 $\times 100 \mathrm{~mm}$ cylindrical specimens according to rock mechanics test standard (Bieniawski and Bernede 1979). Four axial strain gauges and two transverse strain gauges with size of $2 \times 10 \mathrm{~mm}$ were arranged symmetrically on the surface of middle area of the specimen, which would measure the axial strain and transverse strain, respectively. Strain datum was recorded in real time using XL2101C programmable static resistance strain monitor. SANS servo testing machine was used to conduct loading, which has the maximum loading capacity as $200 \mathrm{kN}$. Displacement control loading model was adopted, and the loading and 
unloading rate was $0.05 \mathrm{~mm} / \mathrm{min}$. Cyclic loading test also conducted on the two kinds of marble, in first loading cycle, the loading level was set to $1 \mathrm{MPa}$, when loading value reached $1 \mathrm{MPa}$ then unloading the specimen; in second loading cycle, the loading level was $2 \mathrm{MPa}$, and in third cycle the level was $3 \mathrm{MPa}$, etc. The loading cycles are added continuously till the specimen is fractured in the test. There were eight specimens had been prepared for each kind of marble, and named to $\mathrm{A} 1-\mathrm{A} 8$ and $\mathrm{B} 1-\mathrm{B} 8$, respectively. A1-A5 and B1-B5 were tested in direct tensile loading, and A6-A8 and B6-B8 were tested in cyclic tensile loading. AE signals were collected by DS5.0 AE monitor with a sampling frequency of $3 \mathrm{mHz}$. PAC's Nano-30 AE sensors were adopted, whose best response frequency range was $125-750 \mathrm{kHz}$. The preamplifier gain was $40 \mathrm{~dB}$ and threshold was set to $10 \mathrm{mV}$. Both ends of the specimen were evenly arranged with three AE sensors which were homologous in upper and lower position with $120^{\circ}$ included angle in the center, as shown in Fig. 1. For reason that the power system of SANS machine is in its lower part, the signals of channel 3 which connect to a sensor on the upper end of specimens was chosen to analyzed in the article.

\section{Experiment results}

\subsection{Mechanical parameter of the specimens}

The main mechanical parameters of the two kinds of rocks (pink coarse-grained marble and white fine-grained marble) were obtained via uniaxial tensile and compressive test. For specimens in the compressive test, take the average value of test results of each group, as shown in Table 1. The uniaxial tensile stress-strain curves of two kinds of specimens are shown in Fig. 2.

The two kinds of marble are middle hard rock. For pink marble in group $\mathrm{A}$, the average compressive strength is 92.7 $\mathrm{MPa}$, average tensile strength is $3.5 \mathrm{MPa}$ and compressive strength and tensile strength ratio( $\mathrm{C}-\mathrm{T}$ ratio) is 26.5; for white marble in group $\mathrm{B}$, the average compressive strength is $86.4 \mathrm{MPa}$, tensile strength is $6.5 \mathrm{MPa}$ and C-T ratio is 13.3. Although marble is relatively homogeneous rock, the uniaxial tensile strengths of these specimens are with big discreteness. The standard deviation of group A is $0.63 \mathrm{MPa}$, its ratio to average value is 0.18 ; standard deviation of group B is $1.12 \mathrm{MPa}$, its ratio to average value is 0.17 . For specimens of both groups, compressive strength is not proportional to tensile strength. From fracture surface of specimens (Fig. 3), specimen in group A is coarse-grained marble comprising coarse particles with size around $1 \mathrm{~mm}$ and sticking substance. The strength of sticking substance between particles under tensile state is

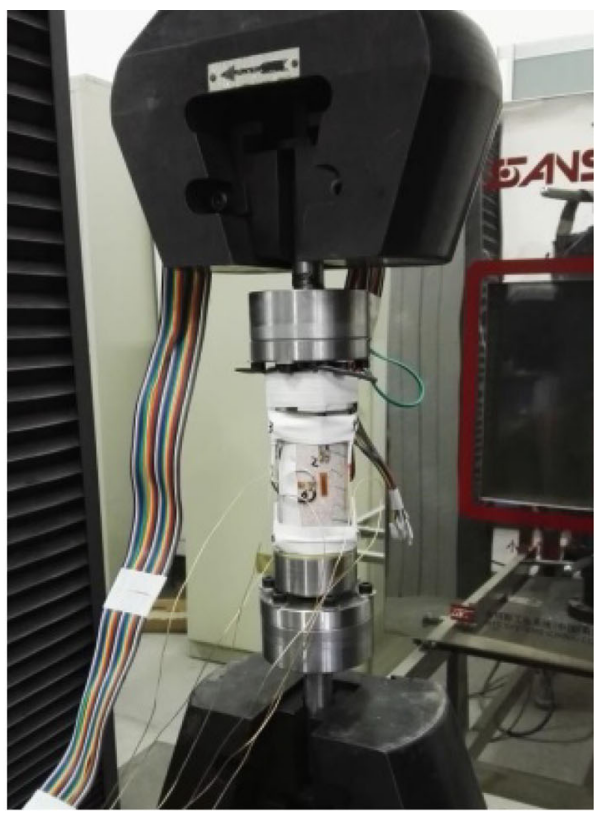

(b)

Fig. 1 The sketch and photo of set-up for direct tensile AE test on rock specimens. a Schematic diagram of test device, $\mathbf{b}$ photo of the mounted specimen 
Table 1 Mechanical parameters of the two kinds of marble specimens

\begin{tabular}{|c|c|c|c|c|c|c|c|}
\hline Test method & No. & $\begin{array}{l}\text { Density } \rho \\
\left(\mathrm{kg} / \mathrm{m}^{3}\right)\end{array}$ & $\begin{array}{l}\text { Longitudinal wave } \\
\text { velocity } v_{p}\left(\mathrm{~m} / \mathrm{s}^{1}\right)\end{array}$ & $\begin{array}{l}\text { Elastic } \\
\text { modulus } E_{c} \\
(\mathrm{GPa})\end{array}$ & $\begin{array}{l}\text { Compressive } \\
\text { strength } \sigma_{c} \\
\text { (MPa) }\end{array}$ & $\begin{array}{l}\text { Tensile } \\
\text { strength } \sigma_{t} \\
\text { (MPa) }\end{array}$ & $\begin{array}{l}\text { Ratio between compressive } \\
\text { and tensile strength }\end{array}$ \\
\hline \multirow[t]{2}{*}{$\begin{array}{l}\text { Compressive } \\
\text { test }\end{array}$} & $\begin{array}{c}\text { Group } \\
\text { A }\end{array}$ & 2718 & 4699 & 53.4 & 92.7 & - & - \\
\hline & $\begin{array}{l}\text { Group } \\
\text { B }\end{array}$ & 2736 & 4970 & 69.8 & 86.4 & - & - \\
\hline \multirow[t]{12}{*}{ Tensile test } & A1 & 2715 & 4667 & - & - & 4.2 & 22.1 \\
\hline & $\mathrm{A} 2$ & 2718 & 4651 & - & - & 3.7 & 25.1 \\
\hline & A3 & 2707 & 4794 & - & - & 3.2 & 29.0 \\
\hline & A4 & 2705 & 4811 & - & - & 4.1 & 22.6 \\
\hline & A5 & 2718 & 4609 & - & - & 2.5 & 37.1 \\
\hline & Average & 2713 & 4706 & & & 3.5 & 26.5 \\
\hline & B1 & 2726 & 5587 & - & - & 7.2 & 12.0 \\
\hline & B2 & 2689 & 5692 & - & - & 7.5 & 11.5 \\
\hline & B3 & 2708 & 5622 & - & - & 7.3 & 11.8 \\
\hline & B4 & 2713 & 5275 & - & - & 4.6 & 18.8 \\
\hline & B5 & 2732 & 5087 & - & - & 5.8 & 14.9 \\
\hline & Average & 2714 & 5453 & & & 6.5 & 13.3 \\
\hline
\end{tabular}

obviously smaller than that of the particles, so tensile fracture mainly occurs in the sticking substance. Specimens in group B are dense fine-grained marble with well homogeneity, so the elastic modulus and tensile strength are higher. In the compressed state, the micro weak parts between particles of group A has little effect on macro shear and friction damage, as well as coarse particles have higher shear strength, so the compressive strength of group A marble is higher than that of group B. It also shows that mechanical response of rock material is related to stress state in addition to its own mineral composition and structure. The mechanical constitutive and strength criterion of rock under direct tensile state should be discussed specially.

The tensile stress-strain curves in Fig. 2 show that the whole tensile process of specimens in group A are almost nonlinear. The tensile tangent modulus decreases monotonically with increasing of stress level, indicating that tensile strength between inner particles of the specimens are strong unevenness. The tensile stress-strain curves of specimens in group B were basically linearly increased in whole loading process, especial for specimen B1, B2 and B3, indicating that tensile strengths of internal crystal of specimens in group B are relatively uniform. In addition, tensile modulus of specimens in group B is also significantly higher and more uniform than that in group A. As shown in Fig. 2b, linear parts of tensile curves of B1-B4 are almost completely coincided.

\subsection{AE activity for specimens under direct tensile process}

Figures 4 and 5 shows AE activity of the two kinds of marble specimens during direct tensile test, where $\sigma_{v}$ and $\varepsilon_{v}$ is the vertical stress and strain in tensile test, respectively. The relationship between stress, AE energy rate and axial strain are given. Compared to the numbers of $\mathrm{AE}$ events occur in compressive tests (Hou 2017), there are obviously less in direct tensile test and almost no AE events were detected at the initial loading stage. The energy of most AE events is less than $300 \mathrm{mV}$ except few AE events occurring at macroscopic fractured moment. In comparison of the two groups' marble, AE events for group A occurred earlier and with more quantity during the whole loading process than group B. Obvious AE activity occurs after loading level exceeding $80 \%$ of damage strength for the specimen B2. The first half loading stage of specimen B5 is almost linear, and almost no AE occurs. While, when loading level exceeds $50 \%$ of B5's tensile strength, AE events begins to occur in large quantity, and the loading process becomes to non-linear.

\subsection{AE activity in tensile cyclic loading test}

Figure 6 shows the stress-strain curves for two groups of marble under directly tensile cyclic loading. It can be seen that cyclic loading has no significant effect on tensile strength and failure process of the specimens. Similar to 


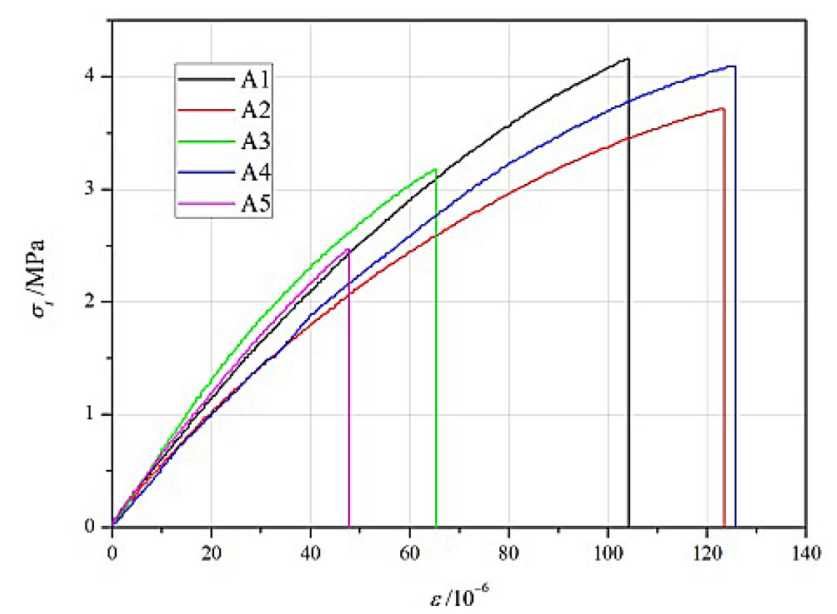

(a)

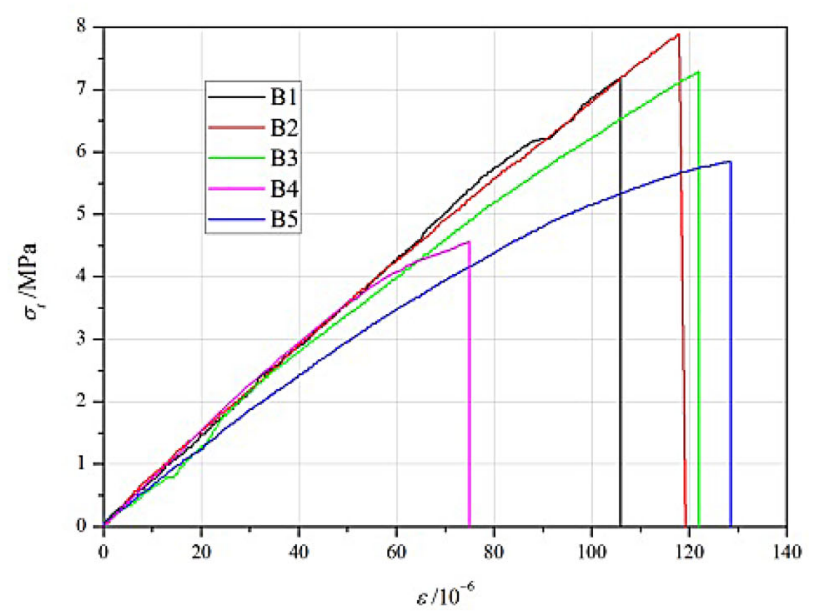

(b)

Fig. 2 Tensile stress-strain curves of marble specimens in the two groups. a Group A, b Group B

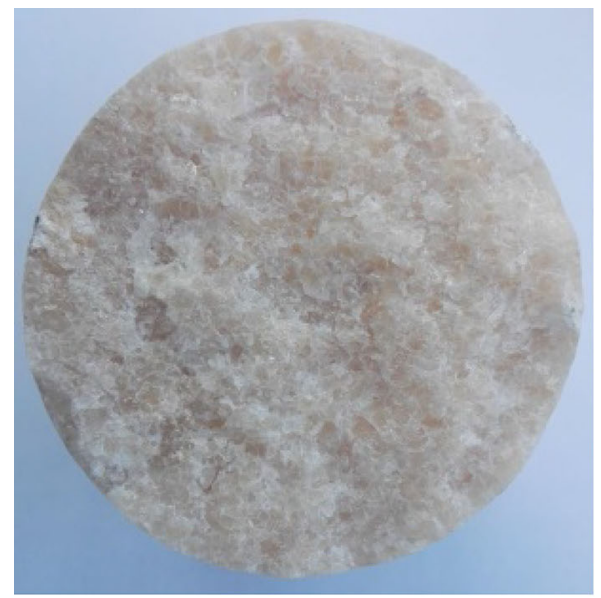

(a)

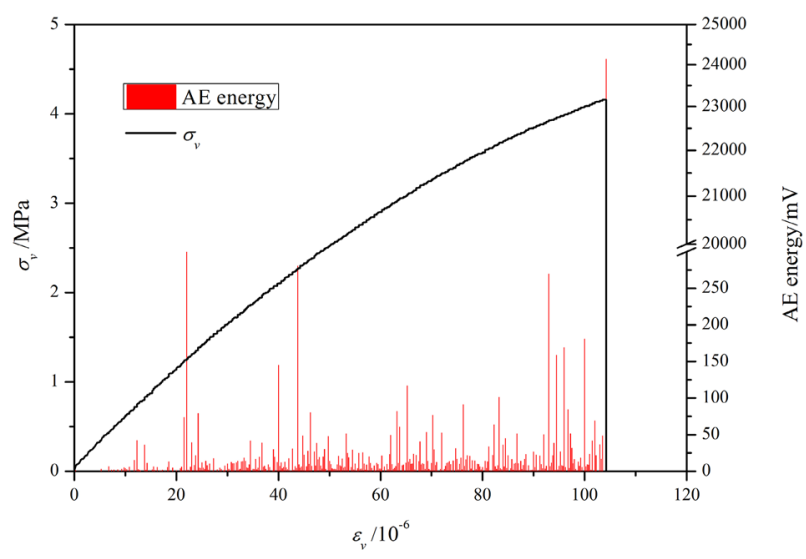

(a)

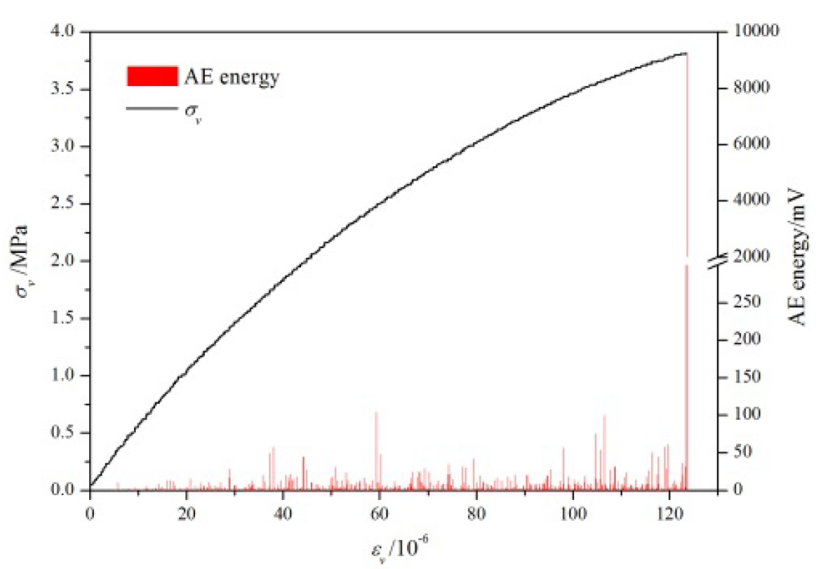

(b)

Fig. $4 \mathrm{AE}$ activities during the whole directly tensile process for specimens in A group. a Specimen A1, b specimen A2

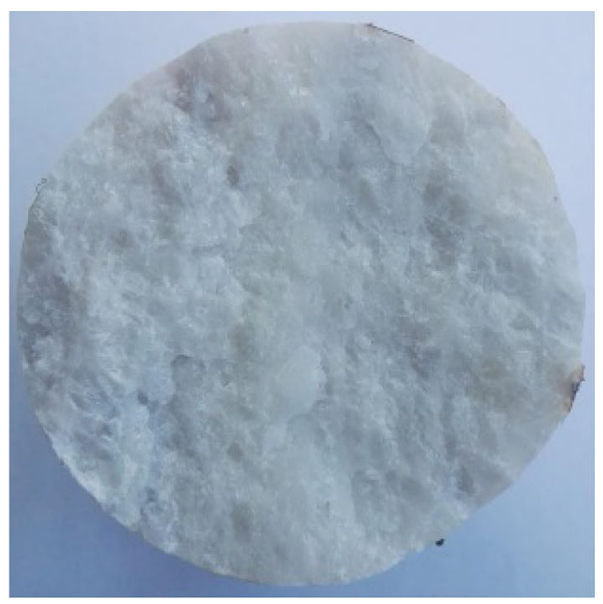

(b)

Fig. 3 Photographs of fracture surface for two marble specimens. a Specimen A2, b specimen B3 


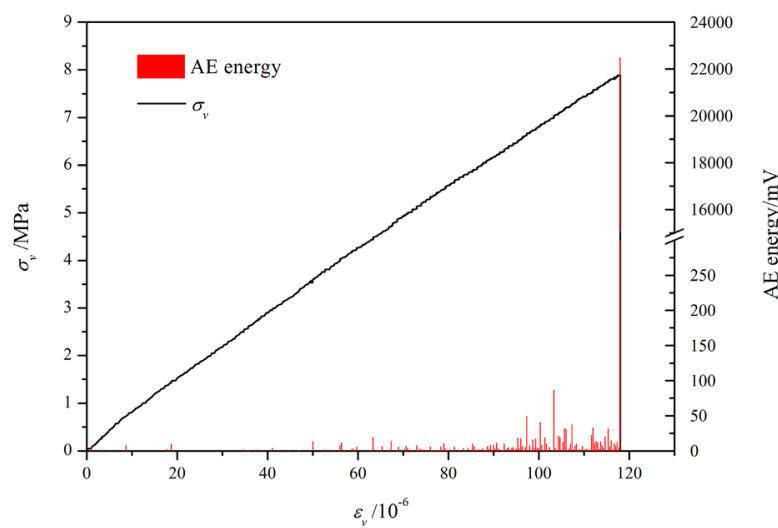

(a)

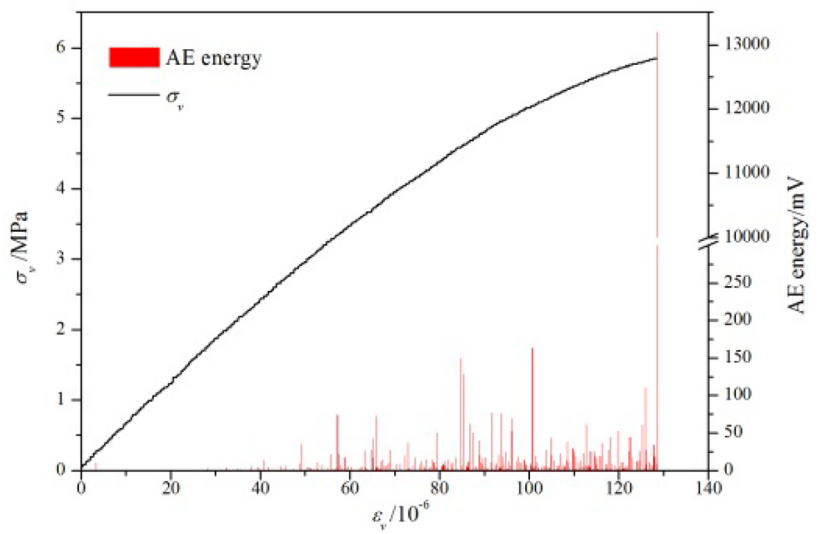

(b)

Fig. 5 AE activities during the whole directly tensile process for specimens in B group. a Specimen B2, b specimen B5

axial compression cyclic loading, tensile loading and unloading process cannot be repeated yet, and the next loading cycle is linear when loading stress level is less than that in the previous loading cycle, and becomes to nonlinear when it exceeds the previous loading level.

The internal microcracks of the specimen increases with increasing of tensile loading, the portions of inner particles that can bear tensile stress decreases, and the decreasing of tangent modulus is the apparent behavior. During unloading cycle, the unspoiled particles recover its deformation, but the failure particles such as the generation and propagation of microcracks cannot be recovered. Portion of loading energy is consumed with the increasing of microcracks. In reloading cycles, the portions that can bear tensile loading in specimen is reduced compared with the previous loading, resulting in the reducing of its tensile modulus which shown in weakened linear characteristic. This is opposite to reloading linear characteristic that reinforcement in compression cyclic loading for rock specimens (You 2007). Figure 7 shows the variation of tensile modulus of the two kinds of marble under different loading cycles. It can be seen that specimens in group B with more uniform and compact particles has less reduction

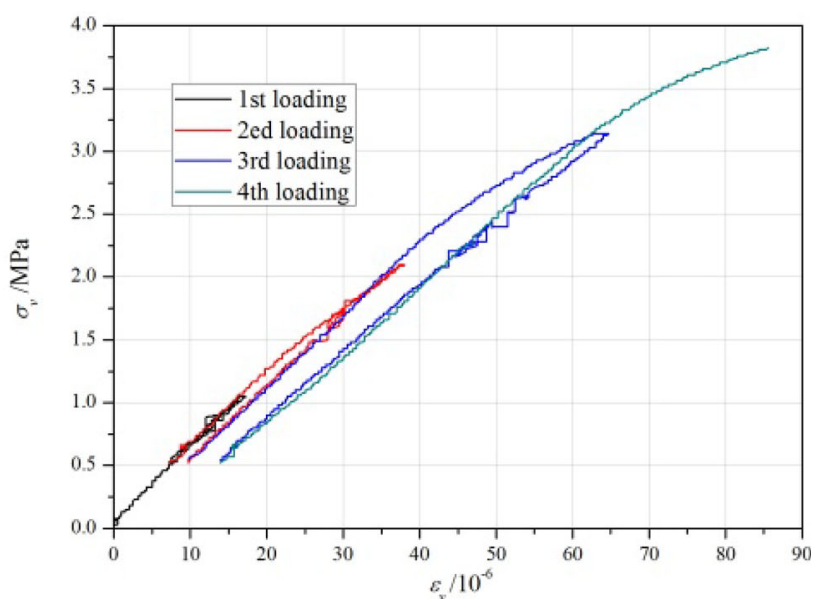

(a)

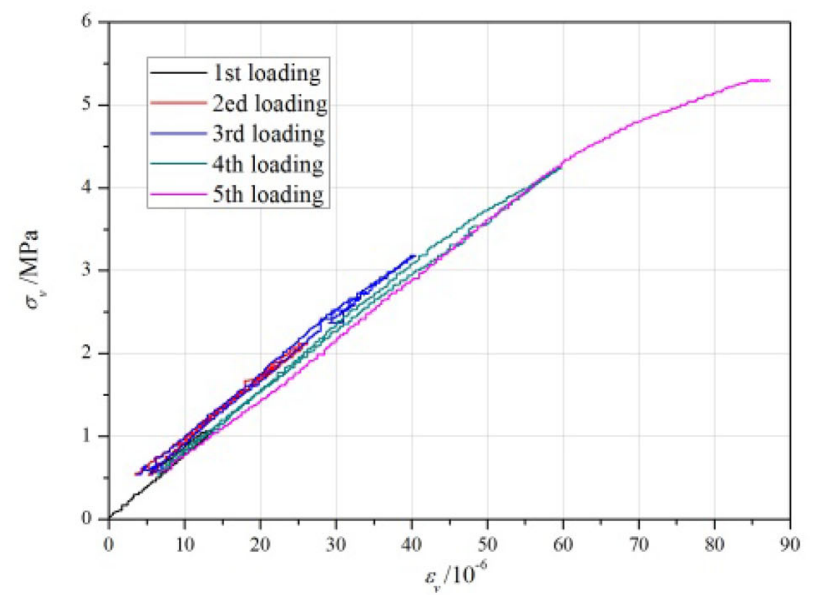

(b)

Fig. 6 Stress-strain curves in cycle tensile loading for the two groups of specimens. a A6 specimen, b B6 specimen

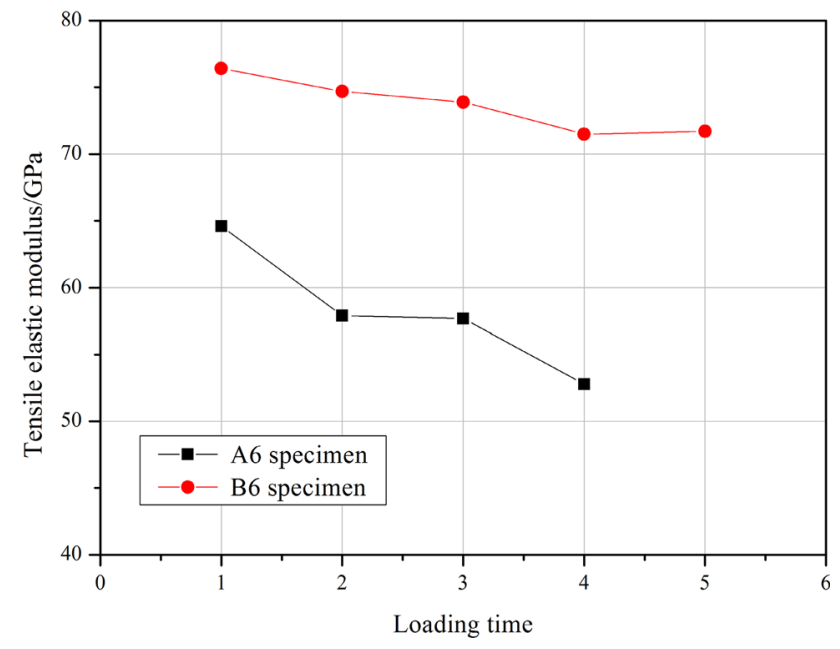

Fig. 7 Variation of elastic modulus in different tensile loading cycle

in elastic modulus in the cyclic loading. While specimens in group A with stronger non-uniformity has larger 
reduction in elastic modulus in the cyclic loading and each cyclic tensile process produces more micro damage in it.

Figure 8 shows the relationship of loading level and AE cumulative energy during the tensile cyclic loading process. The KE Points refers to Kaiser Effect point that occurs when AE activity recovers during repeated loading. There is also significant Kaiser Effect during tensile cyclic loading on rock specimens. AE signal reappears when loading stress level is beyond maximum stress level in previous loading. There is no AE signal occurrence during the unloading process. The Kaiser Effect in tensile loading also proves the phenomenon of damage accumulation in rock material under tensile state.

\section{Tensile constitutive equation based on AE energy}

AE event is an accompaniment signal of generation of micro-crack within the rock. Its quantity and magnitude reflect density and size of micro-cracks, especially for the rock specimens in direct tensile state. Because there is

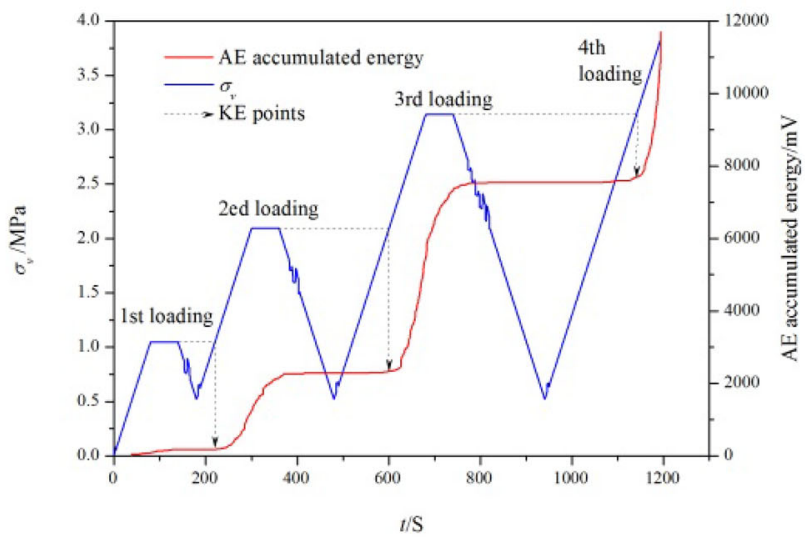

(a)

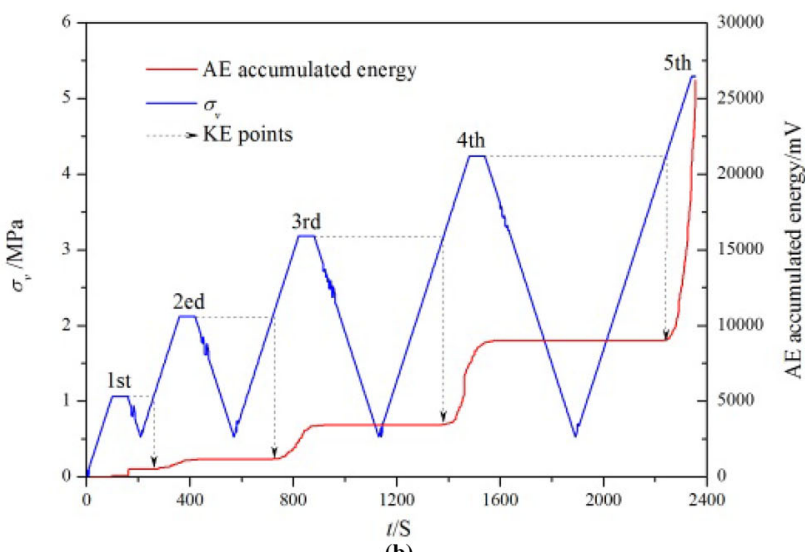

Fig. 8 Variation of stress and AE energy in the tensile cyclic loading, a A6 specimen, b B6 specimen almost no noise signal caused by loading contact and sliding friction of particles, AE signals and tensile microdamage have a better correspondence.

\subsection{Tensile damage factor}

The basic principle of damage mechanics is that the main mechanism of material deterioration is decreasing of effective bearing area caused by micro-defect. Hence, concept of damage factor is introduced (Rabotnov 1969):

$D=\frac{A_{\mathrm{d}}}{A}$

where $D$ is damage factor, $D=0$ for completely nondamaged state of material, $D=1$ for completely loss of bearing loading capacity. $A$ is the area with damage, that is, apparent area of the specimen; $A_{\mathrm{d}}$ is the total area of microdefect of specimen, $\left(A-A_{\mathrm{d}}\right)$ is effective bearing area. For non-uniform rock materials, area of micro-defects is difficult to measure, especially in the process of loading, as micro-fracture area will change with the load increasing.

Assuming that the marble specimen is intact material before tensile loading, the occurrence of $\mathrm{AE}$ events indicates that generation of damage in the specimens. With cumulative value of $\mathrm{AE}$ energy to indicate the magnitude of internal damage, the damage factor can be defined by AE energy parameter:

$D_{e}=\left(\frac{\sum_{i=1}^{n} e_{i}}{E_{n}}\right)$

where $D_{e}$ is damage factor based on AE energy parameter; $i$ is count of AE event when load is at a certain level; $e_{i}$ is the energy of that $\mathrm{AE}$ event; $E_{n}$ is the total accumulative energy of AEs when the specimen is completely failure, its value can be obtained through $\mathrm{AE}$ experiments. Since $e_{i}$ and $E_{n}$ are respectively energy of single $\mathrm{AE}$ event and cumulative energy with the same unit, $D_{e}$ is dimensionless quantity.

\subsection{Damage constitutive model in tensile state for rock material}

According to the aforementioned test results, the essence of tensile stress-strain relationship is the process of generation and propagation of micro-cracks in the rock. The damaged portion of specimens have lost the ability to bear tensile stress, but stress-strain relationship of the rest portion which bear the tensile loading still conforms to Hooke's law for elastic material.

$\tilde{\sigma}_{t}=\frac{F_{t}}{A-A_{d}}=E \varepsilon$

where $\tilde{\sigma}_{t}$ is effective stress; $F_{t}$ is applied tensile loading; $E$ 


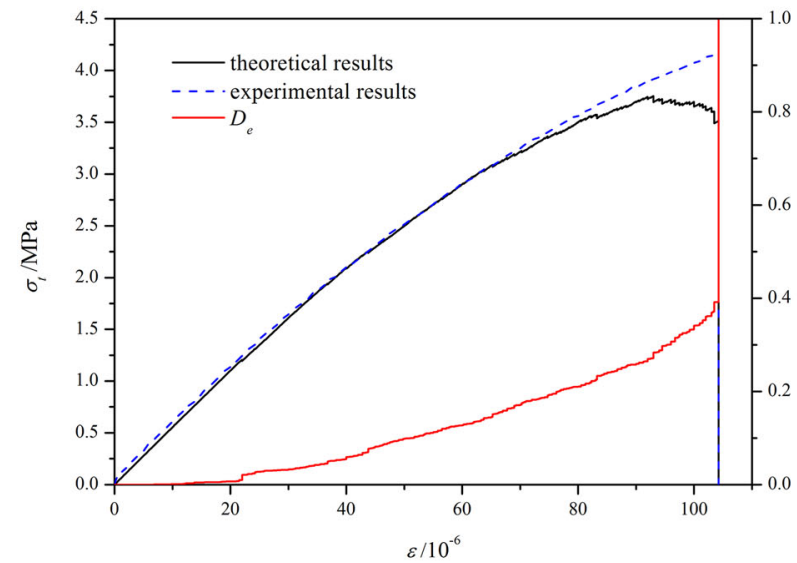

(a)

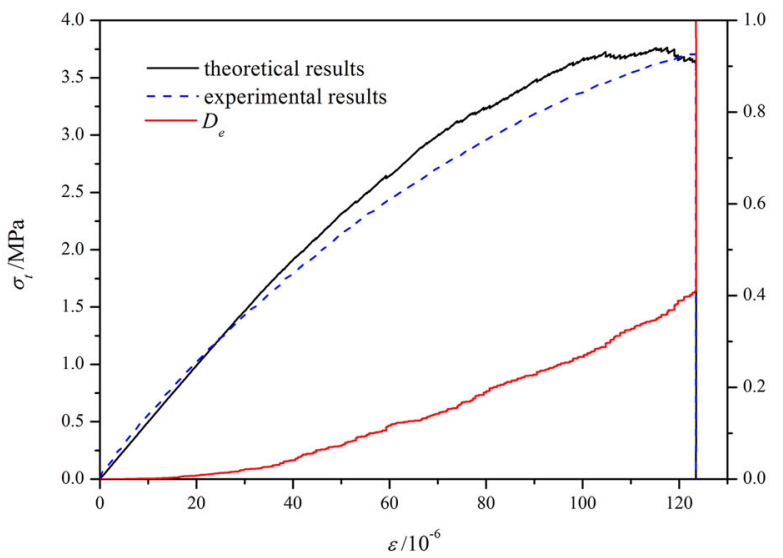

(b)

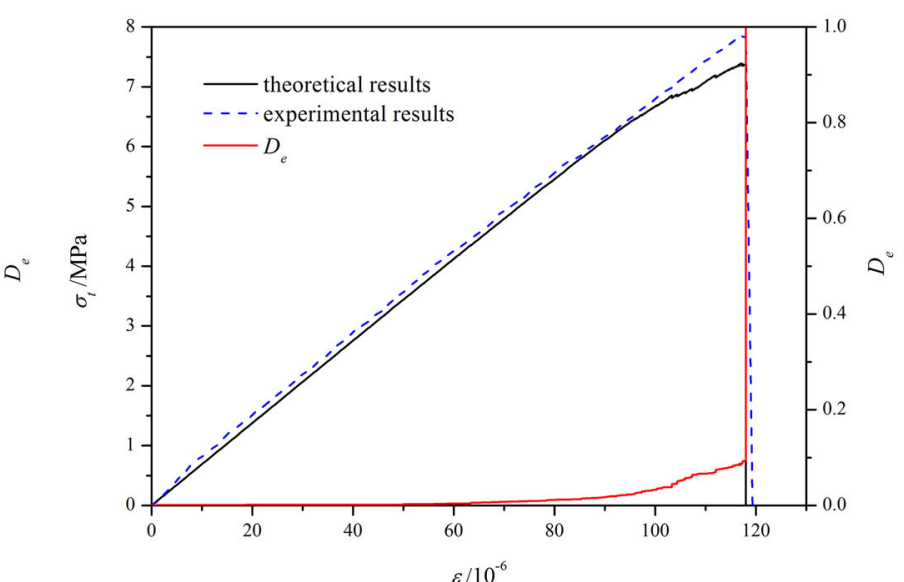

(c)

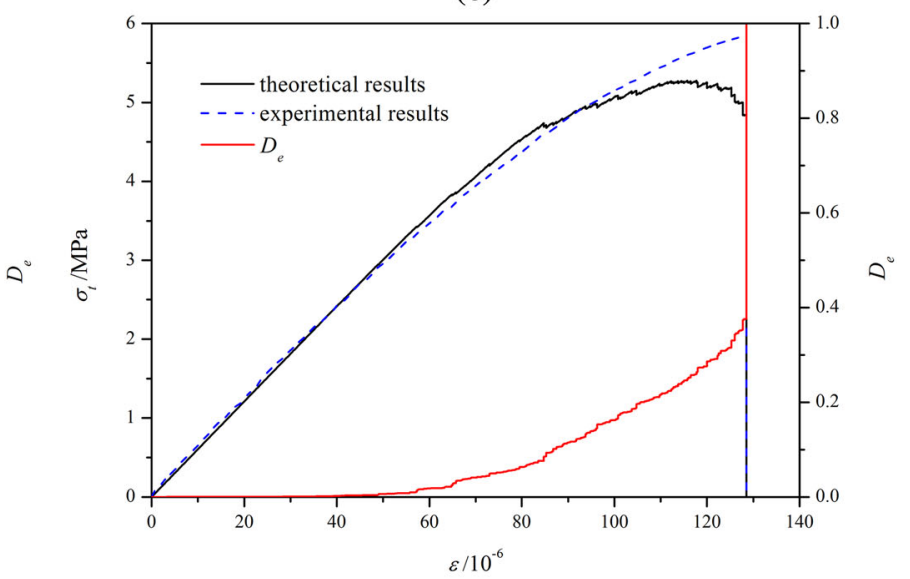

(d)

Fig. 9 Comparison of the theoretical simulated results based on AE energy factor and the test results. a Specimen A1, b specimen A2, c specimen B2, d specimen B5

is elastic modulus of the loaded material; $\varepsilon$ is strain. Substitute Eq. (1) in, then Eq. (3) can be expressed with damage factor:

$\sigma_{t}=E \varepsilon(1-D)$

Substitute the damage factor $D_{e}$ which defined by $\mathrm{AE}$ energy into Eq. (4), then:

$\sigma_{t}=E \varepsilon\left(1-D_{e}\right)=E \varepsilon\left[1-\left(\frac{\sum_{i=1}^{n} e_{i}}{E_{n}}\right)\right]$

Figure 9 shows the comparison of theoretical and experimental results of stress-strain relationship for the two kinds of marble, and the variation of damage factor with strain increasing. It can be seen that the theoretical simulation curve based on AE energy parameters can well represent directly tensile stress-strain relationship for the two kinds marble.

The constitutive equation in formula (5) contains only two constants, i.e., initial elastic modulus and cumulative AE energy of the rock, which represent material characteristics and accumulative amount of internal microdefects respectively, indicating that quasi-static tensile failure process of rock is determined by the two constants. Compared with other tensile damage equations (Qin et al. 2003; Zhou and Xu 2009), the constants of initial damage factor is taken out and the initial value of specimen's damage factor $D_{e}$ is 0 for all rock material. Although ideal rock material without any defects is not reality, it is hard to quantize the initial damage level in practical application. In addition, the initial elastic modulus which can be easily gotten from test has contained the initial damage factor implicitly. If initial damage value is added to the equation, then the initial damage factor would be considered repeatedly. The damage parameter $D_{e}$ which initial level is 0 in Eq. (5) accumulatively increases in the loading process and mutates to the level $D_{e}=1$ when the maximum tensile strain is reached, which indicates the transition of gradual micro-damage accumulation to sudden macroscopic fracture in rock specimens. 
The two material constants in this tensile constitutive equation can be tested by $\mathrm{AE}$ system and servo test machine. Due to the directly tensile state, AE signal is less disturbed by loading noise, and the threshold value collected by $\mathrm{AE}$ equipment can be set on a lower level, so that more AE signals, especially low energy signals, can be collected. Meanwhile, AE signals should be collected via multiple channels, and the average value of cumulative $\mathrm{AE}$ energy from all acquisition channels could be taken to reduce error that collected by only single channel.

\section{Conclusions}

The directly tensile tests on two kinds of marble specimens were conducted and the AE signal were acquired and analyzed. The mechanical response and characteristic of $\mathrm{AE}$ activity under directly tensile process were obtained. The tensile constitutive equation based on AE energy parameters was proposed and cumulative damage character for marble specimens was analyzed. Following conclusions can be drawn:

(1) Tensile strength of marble has a strong discreteness, which is more sensitive to micro-defects and particle composition within the rock. The tensile stressstrain curve is obviously nonlinear, with tensile tangent modulus decreasing with the load increase. In the cyclic loading, elastic modulus of the specimen decreases compared with that in the previous loading, and showed that its linearity decreases due to increasing of internal micro-defect in it.

(2) Compared with AE signal in compressive test, it has less quantity and smaller energy in the directly tensile tests. AE activity is well corresponding to nonlinear deformation of specimens under tensile loading process. At the initial stage of elastic deformation, almost no AE event occurs, but at nonlinear deformation stage, $\mathrm{AE}$ occurs in large volumes, and its quantity and energy relate to the variation of tensile tangent modulus. AE Kaiser Effect can be clearly observed during tensile cyclic loading.

(3) Based on the theory of damage mechanics, the damage factor of rock material were proposed by $\mathrm{AE}$ energy, and tensile damage constitutive equation needing two material constants was established, which was proved to be in good agreement with the experimental result.

Open Access This article is distributed under the terms of the Creative Commons Attribution 4.0 International License (http://crea tivecommons.org/licenses/by/4.0/), which permits unrestricted use, distribution, and reproduction in any medium, provided you give appropriate credit to the original author(s) and the source, provide a link to the Creative Commons license, and indicate if changes were made.

\section{References}

Bieniawski ZT, Bernede MJ (1979) Suggested methods for determining the uniaxial compressive strength and deformability of rock materials: part 1. Suggested method for determining deformability of rock materials in uniaxial compression. Int $\mathbf{J}$ Rock Mech Min Sci Geomech Abs 16(2):138-140

Cao AY, Dou LM, Wang CB et al (2016) Microseismic precursory characteristics of rock burst hazard in mining areas near a large residual coal pillar: a case study from Xuzhuang Coal Mine, Xuzhou, China. Rock Mech Rock Eng 49(11):4407-4422

Chen L, Liu JF, Wang CP et al (2012) Study of acoustic emission characteristics of Beishan deep granite under different stress conditions. Chin J Rock Mechan Eng 31(s2):3618-3624 (in Chinese)

Hall S, Sanstis F, Viggiani G (2006) Monitoring fracture propagation in a soft rock (Neapolitan Tuff) using acoustic emissions and digital images. Pure Appl Geophys 163(10):2171-2204

He J, Pan JN, Wang AH (2014) Acoustic emission characteristics of coal specimen under triaxial cyclic loading and unloading. J China Coal Soc 39(01):84-90 (in Chinese)

Hou ZQ (2017) Research on mechanical properties and acoustic emission activities of rock specimens under direct tension (Master Thesis). Henan Polytechnic University, pp 25-26 (in Chinese)

International Society for Rock Mechanics (1978) Suggested methods for determining tensile strength of rock materials. Int J Rock Mech Min Sci Geomech Abs 15:100

Jiang D, Chen J, Ren S, Xi Y, Yang C (2013) A damage constitutive model of rock salt based on acoustic emission characteristics. In: Hou M, Xie H, Were P (eds) Clean energy systems in the subsurface: production, storage and conversion. Springer Series in Geomechanics and Geoengineering. Springer, Berlin

Jin FN, Qian QH (1998) Uniaxial tension and mechanical model of rock. Chin J Geotech Eng 20(06):8-11 (in Chinese)

Katsuyama K (1996) Application of acoustic emission (AE) technology (trans: Feng Xiating). Metallurgical Industry Press, Beijing (in Chinese)

Li HG, Li HM (2017) Mechanical properties and acoustic emission characteristics of thick hard roof sandstone in Shendong coal field. Int J Coal Sci Technol 4(2):147-158

Li DY, Li XB, Li CC (2010) Experimental studies of mechanical properties of two rocks under direct compression and tension. Chin J Rock Mechan Eng 29(3):624-632 (in Chinese)

Li TY, Liu JF, Chen L et al (2013) Acoustic emission characteristics of granite under tensile loading. Chin J Rock Mechan Eng 32(S2):3215-3221 (in Chinese)

Liu XL, Pan MC, Li XB et al (2017) B-value characteristics of rock acoustic emission under impact loading. In: Shen G, Wu Z, Zhang J (eds) Advances in acoustic emission technology. Springer Proceedings in Physics, vol 179. Springer, Cham

Nasseri MHB, Mohanty B, Young RP (2011) Fracture toughness measurements and acoustic emission activity in brittle rocks. Pure Appl Geophys 165(5-6):917-945

Přikryl R, Lokajíček T, Li C et al (2003) Acoustic emission characteristics and failure of uniaxially stressed granitic rocks: the effect of rock fabric. Rock Mech Rock Eng 36(04):255-270 
Qin YP, Zhang JF, Wang L (2003) Preliminary discussion on theoretical model of rock damage mechanics. Chin J Rock Mechan Eng 22(04):646-650 (in Chinese)

Rabotnov YN (1969) Creep ruptures. Applied mechanics. Springer, Berlin, pp 342-349

Stavrogin AN, Zaretskii-Feoktistov GG, Tanov GN (1986) Study of acoustic emission during deformation of rocks under conditions of a complex axisymmetric stressed state. Sov Min 22(05):341-350

Tham LG, Liu H, Tang CA et al (2005) On tension failure of 2-D rock specimens and associated acoustic emission. Rock Mech Rock Eng 38(01):1-19

Wang SR, Li CY, Yan WF et al (2017) Multiple indicators prediction method of rock burst based on microseismic monitoring technology. Arab J Geosci 10:132
Xiao YX, Feng XT, Hudson JA et al (2016) ISRM suggested method for in situ microseismic monitoring of the fracturing process in rock masses. Rock Mech Rock Eng 49(01):343-369

You MQ (2007) Rock mechanics properties. Geological Publishing House, Beijing (in Chinese)

Yu Y, Zhang ZX, Yu J et al (1998) Energy dissipation and damage characters in rock direct tensile destruction. Chin J Rock Mechan Eng 17(04):38-44 (in Chinese)

Zhou JW, Xu WY (2009) Investigation on the micro-crack damage model of brittle rock under uniaxial tensile loading. Chin J Solid Mech 30(05):509-514 (in Chinese) 